\title{
Effect of vegetable oils on the colour stability of four tropical woods during natural and artificial weathering
}

\author{
Miloš Pánek ${ }^{1} \cdot$ Ladislav Reinprecht $^{2}$
}

Received: 6 May 2015/Accepted: 17 September 2015/Published online: 22 October 2015

(C) The Japan Wood Research Society 2015

\begin{abstract}
The aim of this paper was to study effect of transparent and pigmented vegetable oils on the colour stability of selected tropical woods during their natural and artificial weathering. The surfaces of four tropical woods recommended for garden furniture and outdoor architecture-kusia (Nauclea diderrichii Merill), bangkirai (Shorea obtusa Wall., Sh. spp.), massaranduba (Manilkara bidentata A. Chev.; M. spp.) and jatobá (Hymenaea courbaril L.) were treated with vegetable oil Woca "Exterior Oil Exclusive" of the transparent, teak or bangkirai shade. Native samples of these wood species were also tested. Both weathering processes, the natural according to EN 927-3, lasting 1-36 months, and the artificial in Xenotest according to modified EN 927-6, lasting 1-12 weeks, showed that the colour coordinates $L^{*}, a^{*}, b^{*}$ changed more in the early stages of weathering. Bangkirai wood treated with teak oil had the best colour stability. The highest changes of the colour coordinates $\Delta L^{*}, \Delta a^{*}, \Delta b^{*}$ and the total colour difference $\Delta E^{*}$ occurred for kusia wood treated with transparent oil. Linear correlation of $\Delta E^{*}$ was the highest between 12 months of outdoor weathering and 4 weeks of artificial weathering but results were not always clear for the most other compared cases.
\end{abstract}

Miloš Pánek

panekmilos@fld.czu.cz

1 Faculty of Forestry and Wood Sciences, Czech University of Life Sciences Prague, Kamýcká 129,

16521 Prague 6-Suchdol, Czech Republic

2 Faculty of Wood Sciences and Technology, Technical University in Zvolen, Masarykova 24, 96053 Zvolen, Slovak Republic
Keywords Tropical wood - Vegetable oil · Pigment . Weathering · Colour stability

\section{Introduction}

Tropical wood species are usually characterised by a high durability against biodegradation agents due to the presence of specific extractive substances-flavonoids, tannins, etc. However, to the colour changes of wood exposed in exterior conditions significantly contribute not only extractives [1-4], but also lignin [5-7]. The colour changes of some tropical woods caused by weathering were observed in more scientific papers [1, 2, 8-10]. Generally, the colour stability of tropical woods significantly depends not only on the wood species and the surface treatment methods, but also on the area of their exposure [10, 11]. Due to their specific properties, i.e. usually high resistance to biological agents, high density and high resistance to mechanical wear, high-dimensional stability, and good aesthetic, tropical woods are used as wood decking, claddings, garden constructions and furniture in various world regions, including Central Europe.

Therefore, it is convenient to determine for individual tropical wood species the direction and degree of their colour changes in defined local climatic conditions. The aesthetic function of wooden products in the exterior can be extended by selecting the most resistant wood species in terms of colour stability. It is also important to determine the influence of protective coatings on the initial colour of wood before ageing, and the effect of pigments, UV-absorbents or screeners, hydrophobic and other substances present in coatings for reduction of the colour changes of wood surfaces during weathering. Simulation of the natural weathering of painted wood can be done via artificial 
accelerated ageing in Xenotest [12, 13]. However, it is necessary to determine their correlation relations according to different wood species, different finishes and different places of exposure which depend on local weather conditions [11, 14-16]. This problem has not yet been investigated in detail, especially for tropical wood species exposed in the urban or industrial environment of Central Europe.

The aim of this study was to determine the colour stabilisation effect of three vegetable oils applied on four tropical woods exposed to natural and artificial weathering. Simultaneously, using correlation analyses, we wanted to simulate natural weathering with the accelerated weathering in Xenotest.

\section{Materials and methods}

\section{Tropical woods}

Samples without sapwood, knots and other growth inhomogeneity were prepared from boards of four wood species: (1) kusia (Nauclea diderrichii Merill) - $795 \mathrm{~kg} / \mathrm{m}^{3}$, (2) bangkirai (Shorea obtusa Wall., Sh. spp.) $-987 \mathrm{~kg} / \mathrm{m}^{3}$, (3) massaranduba (Manilkara bidentata A. Chev.; M. spp.) - $1012 \mathrm{~kg} / \mathrm{m}^{3}$, (4) and jatobá (Hymenaea courbaril L.) $-907 \mathrm{~kg} / \mathrm{m}^{3}$, conditioned in a climate room at $20{ }^{\circ} \mathrm{C}$ and $65 \%$ RH to a constant moisture content of about $12 \%$. Samples for the natural weathering had a dimensions of $375 \times 78 \times 20 \mathrm{~mm}(\mathrm{~L} \times \mathrm{R} \times \mathrm{T})$ in accordance with $\mathrm{EN}$ 927-3 [17], and those for the accelerated weathering carried out according to a modified EN 927-6 [18] had dimensions of $38 \times 38 \times 8 \mathrm{~mm}(\mathrm{~L} \times \mathrm{R} \times \mathrm{T})$. Top surfaces of samples were grinded along grains with the 120-grit sandpaper. Lateral surfaces of samples were treated with silicone as protection against water.

\section{Vegetable oils}

The Woca Denmark (WoodCare USA LLC) vegetable oil with UV-, water- and mould-protection effects, is a waterbased composition recommended for finishing of wooden products in an exterior. It was used in three colour shades: (a) transparent without pigments "Exterior Oil Exclusive Natural", (b) teak pigmented "Exterior Oil Exclusive Teak", (c) bangkirai pigmented "Exterior Oil Exclusive Bangkirai".

\section{Treatment of tropical woods with vegetable oils}

Samples of four tropical woods conditioned on a moisture content of about $12 \%$ were painted in one layer with the Woca Denmark oils in the amount of $80 \pm 10 \mathrm{~g} \mathrm{~m}^{-2}$. These oils partly changed the initial colours of native tropical woods, even when using transparent oil (Table 1). Salas et al. also observed colour changes of tropical woods after treatment with transparent oils. [19].

\section{Natural and artificial weathering}

The natural weathering of wood samples was carried out from 1st August 2010 to 31st July 2013 in the outside exposition of the Technical University in Zvolen, Slovakia, Central Europe, at a height above sea level of app. $300 \mathrm{~m}$, under a slope of $45^{\circ}$ in south orientation according to EN 927-3 [17]. The exposition place is located in a hollow with
Table 1 Colour parameters of native tropical woods finished with Woca oils

\begin{tabular}{lllllr}
\hline Tropical wood & Colour parameter & \multicolumn{2}{l}{ Woca oils for finishing of woods } & \multirow{2}{*}{ Native samples } \\
\cline { 3 - 5 } & & Transparent & Teak & Bangkirai & \\
\hline \multirow{2}{*}{ Kusia } & $L^{*}$ & $48.0(0.4)$ & $47.7(0.6)$ & $37.9(0.2)$ & $57.9(1.2)$ \\
& $a^{*}$ & $21.3(0.3)$ & $20.2(1.3)$ & $21.6(0.4)$ & $15.6(0.5)$ \\
\multirow{3}{*}{ Bangkirai } & $b^{*}$ & $32.2(0.3)$ & $30.9(0.9)$ & $24.1(0.4)$ & $28.1(0.3)$ \\
& $L^{*}$ & $49.2(1.5)$ & $42.4(0.9)$ & $44.7(0.7)$ & $59.2(1.2)$ \\
& $a^{*}$ & $16.3(0.6)$ & $14.2(0.4)$ & $18.2(0.2)$ & $8.5(0.8)$ \\
Massaranduba & $b^{*}$ & $23.6(1.0)$ & $22.3(0.6)$ & $22.2(0.5)$ & $19.1(0.9)$ \\
& $L^{*}$ & $35.6(1.0)$ & $35.1(0.3)$ & $34.8(0.6)$ & $49.0(0.9)$ \\
& $a^{*}$ & $21.1(1.5)$ & $24.5(0.5)$ & $21.2(0.7)$ & $18.6(0.5)$ \\
& $b^{*}$ & $12.0(1.0)$ & $13.5(0.5)$ & $12.1(0.3)$ & $12.2(0.7)$ \\
& $L^{*}$ & $44.0(1.2)$ & $40.4(1.4)$ & $40.3(0.3)$ & $57.6(0.5)$ \\
& $a^{*}$ & $16.2(0.7)$ & $16.1(0.4)$ & $19.2(0.9)$ & $15.2(0.1)$ \\
& $b^{*}$ & $20.7(0.8)$ & $19.8(1.0)$ & $20.0(0.6)$ & $22.5(0.2)$ \\
\hline
\end{tabular}

Native samples, without any treatment, have also been used in experiment

The mean values in each series are from six measurements $(n=6)$

The numbers in the parentheses are the standard deviations 
Table 2 Climatic conditions during natural weathering from 0 to 36 months, i.e. from the $1 \mathrm{st}$ August 2010 to 31 st July 2013 $[20,21]$

\begin{tabular}{lllllll}
\hline Climatic conditions & \multicolumn{7}{l}{ Exposure time (months) } \\
\cline { 2 - 7 } & $0-1$ & $1-3$ & $3-6$ & $6-12$ & $12-24$ & $24-36$ \\
\hline Temperature $\left({ }^{\circ} \mathrm{C}\right)$ & 18.5 & 8.9 & -2.6 & 14.7 & 9.4 & 9.4 \\
RH $(\%)$ & 86 & 91 & 92 & 77 & 80 & 86 \\
Sum of precipitation $(\mathrm{mm})$ & 87.6 & 256.7 & 92.3 & 373.2 & 538.9 & 860.0 \\
Sum of global radiation $\left(\mathrm{kWh} / \mathrm{m}^{2}\right)$ & 138.2 & 177.7 & 86.6 & 846.4 & 1176.8 & 1089.1 \\
Sum of snow cover days (day) & - & - & 23 & 14 & 68 & 57 \\
\hline
\end{tabular}

$R H$ relative humidity

Table 3 One 1-week cycle of samples' exposure in Xenotest, by modified EN 927-6 [18]

\begin{tabular}{|c|c|c|c|}
\hline \multicolumn{3}{|c|}{ Weathering in Xenotest: one cycle $=1$ week $(168 \mathrm{~h})$} & \multirow{2}{*}{$\begin{array}{l}\text { Functions } \\
\text { Temperature } 45 \pm 3{ }^{\circ} \mathrm{C} \text {, water spray (off), UV (off) }\end{array}$} \\
\hline 1st step & & $24 \mathrm{~h}$ & \\
\hline \multirow[t]{3}{*}{ 2nd step } & A & $2.5 \mathrm{~h}$ & Temperature $50 \pm 3{ }^{\circ} \mathrm{C}$, water spray (off), UV Irradiance $0.55 \mathrm{~W} \mathrm{~m}^{-2}$ at $340 \mathrm{~nm}$ \\
\hline & B & $0.5 \mathrm{~h}$ & Temperature $20 \pm 1{ }^{\circ} \mathrm{C}$, water spray (on), UV (off) \\
\hline & $\mathrm{A}+\mathrm{B}$ & $3 \mathrm{~h}$ & \\
\hline
\end{tabular}

According to EN 927-6 [18]: UV lamps are used instead of an $1800 \mathrm{~W}$ xenon lamp

The prescribed parameters for the test chamber in the 2 nd step/A are as follows: temperature $=60 \pm 3{ }^{\circ} \mathrm{C}, \mathrm{UV}$ irradiance $=0.89 \mathrm{~W} \mathrm{~m}^{-2}$ at $340 \mathrm{~nm}$

a high occurrence of foggy days, smog and high temperature differences between summer (to about $35^{\circ} \mathrm{C}$ ) and winter (to about $-25^{\circ} \mathrm{C}$ ). The climate conditions [20, 21], i.e. the mean temperature, relative humidity, precipitation and solar radiation, were measured daily at the Arboretum Zvolen weather station- $3 \mathrm{~km}$ from our exposition field (Table 2). The natural weathering lasted 36 months with evaluation of the colour parameters of samples after 1, 3, 6, 12,24 , and 36 months.

Artificial weathering of tested samples was carried out in the Q-SUN Xe-1-S Xenotest (Q-Lab Corporation, USA). It lasted 12 weeks and used the modified conditions of the standard EN 927-6 [18] (Table 3). The colour parameters of samples were evaluated after 1, 2, 3, 4, 5, 6, 7, 8, 9, 10, 11 , and 12 weeks.

\section{Colour analyses}

The colours of samples before and after weathering were measured by the Color Reader CR-10 (Konika Minolta, Japan). Six measurements per sample exposed to natural weathering and four measurements per sample exposed to artificial weathering were carried out for each ageing time. Evaluations were done in the CIE- $L^{*} a^{*} b^{*}$ colour system on the basis of $L^{*}, a^{*}$, and $b^{*}$ colour coordinates, where: $L^{*}$ is lightness from 0 (black) to 100 (white), $a^{*}$ is chromaticity coordinate + (red) or - (green), and $b^{*}$ is chromaticity coordinate + (yellow) or - (blue). Relative colour changes of samples $\Delta L^{*}, \Delta a^{*}$ and $\Delta b^{*}$ between their weathered and initial state were determined, and finally, according to the Euclidean distances the total colour differences $\Delta E^{*}$ [22] were calculated by Eq. (1):

$\Delta E=\sqrt{\Delta L^{2}+\Delta a^{2}+\Delta b^{2}}$

\section{Statistical evaluation}

Colour changes related to the species of tropical wood, the type of vegetable oil and the time of weathering in an exterior or in Xenotest were evaluated in the program STATISTICA 10-mean values, standard deviations, Duncan's tests; and, for $\Delta E^{*}$ also linear correlations for modelling the natural weathering by Xenotest.

In the linear correlations, the 12 weeks of artificial weathering were divided into three equal time intervals (after 4, 8 and 12 weeks), and the 36 months of natural weathering into 4 equal time intervals (after 6, 12, 24 and 36 months). Between the total colour differences $\Delta E^{*}$, determined during the artificial and natural weathering, similarities using linear correlations and evaluation of their coefficients of determination were searched for in these defined time intervals $\left(R^{2}\right)$.

\section{Results and discussion}

\section{Effect of tropical wood species on weathering}

From the four tropical wood species tested in their native state, the least colour stable was the kusia wood (see $\Delta E^{*}$ 
Fig. 1 The total colour differences $\Delta E^{*}$ and colour changes $\Delta L^{*}, \Delta a^{*}$, and $\Delta b^{*}$ of native tropical woods during natural weathering for 36 months, and during artificial weathering in Xenotest for 12 weeks
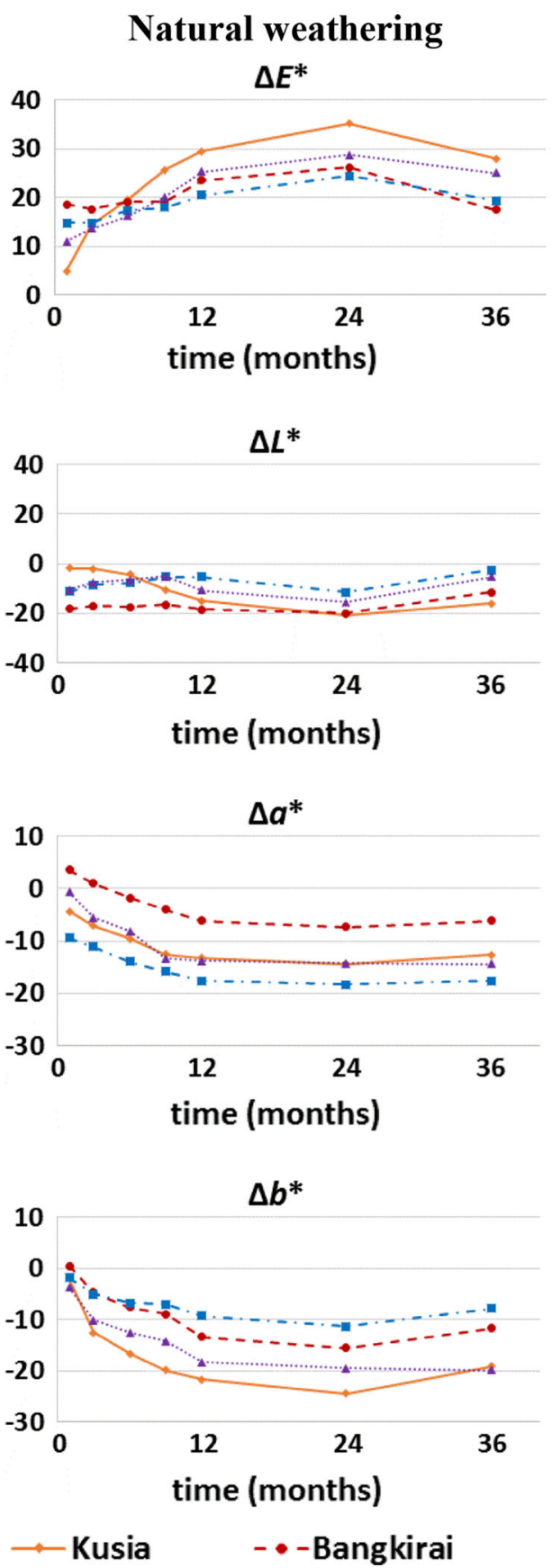

\section{Weathering in Xenotest}
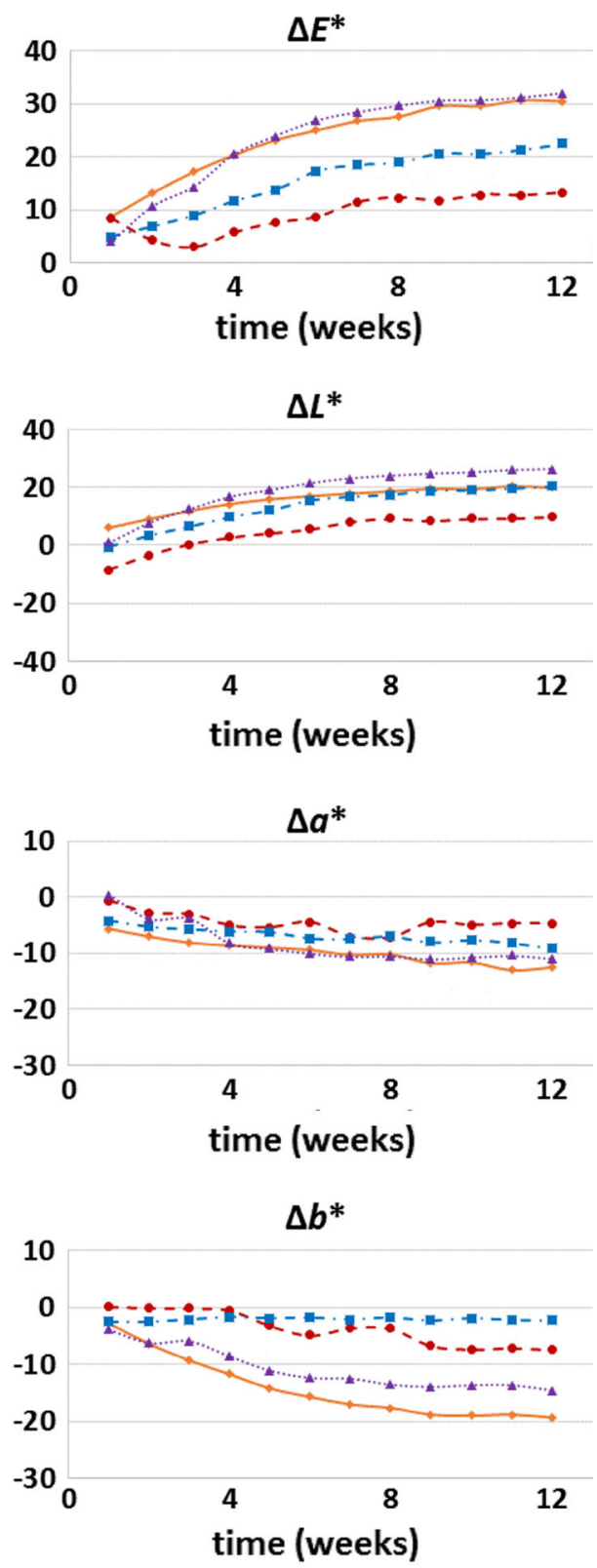

- Massaranduba in Fig. 1), having a light colour (see $L^{*}$ value was 57.9 in Table 1), smaller density (see "Materials and methods"), and non-homogenous porous surface when compared to the other species. Its colour change in an exterior-greying, connected with increase of its green $\left(-a^{*}\right)$, blue $\left(-b^{*}\right)$ and dark $\left(-L^{*}\right)$ shade — was significantly affected by settling of dark dust particles and other impurities into its surface layers. Effects of impurities in combination with other factors for increasing of the colour changes in wood were also observed for other tropical woods tested in this work (Fig. 1), and are also known from other scientific works.
For example, the negative effect of the initial lighter colours of wood was described by Salas et al. [19], the negative effect of a smaller density of wood in the works of Kataoka et al. [23] and Williams et al. [8], and the effect of rougher wood surface in the works of Van den Bulcke et al. [24] and De Windt et al. [25]. The naturally darkest wood species-massaranduba (see $L^{*}$ value was 49.0 in Table 1) darkened in an exterior at least (see $\Delta L^{*}$ in Fig. 1).

Significant colour changes of native kusia and jatobá woods in Xenotest also reflected their small colour stability in an ideal environment, i.e. without the presence of 
Fig. 2 The total colour differences $\Delta E^{*}$ and colour changes $\Delta L^{*}, \Delta a^{*}$, and $\Delta b^{*}$ of tropical woods finished with transparent oil $(\mathrm{T})$ during natural weathering for 36 months, and during artificial weathering in Xenotest for 12 weeks
Natural weathering

$\Delta E^{*}$

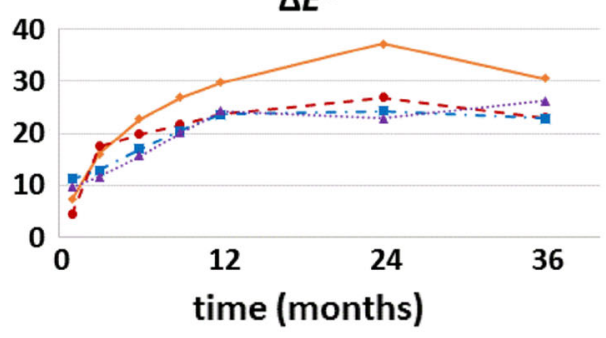

$\Delta L^{*}$

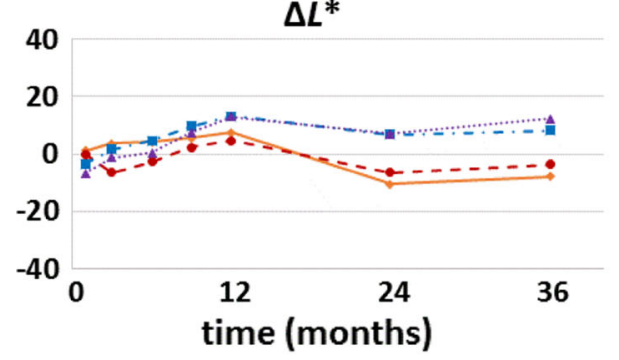

$\Delta a^{*}$

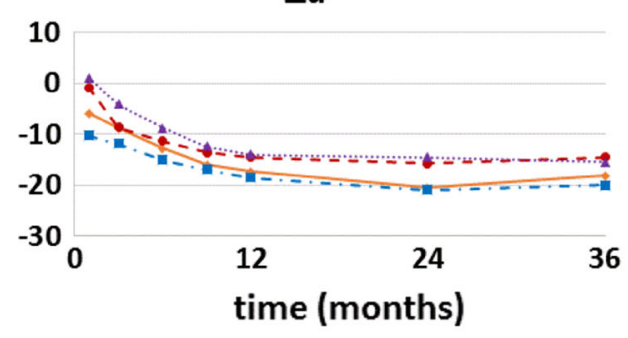

$\Delta b^{*}$

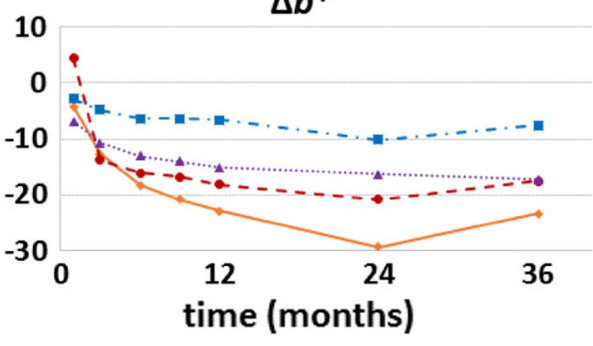

$\rightarrow$ Kusia $\quad-\bullet$-Bangkirai
Weathering in Xenotest
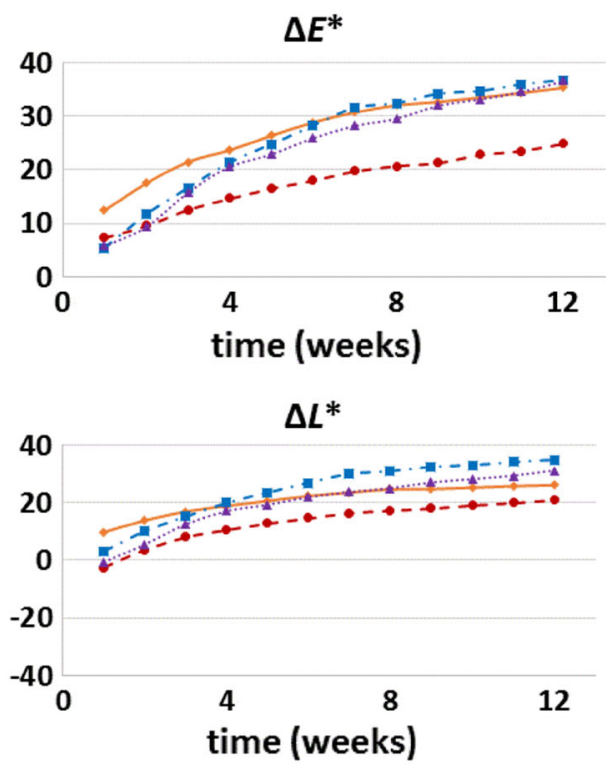

$\Delta a^{*}$
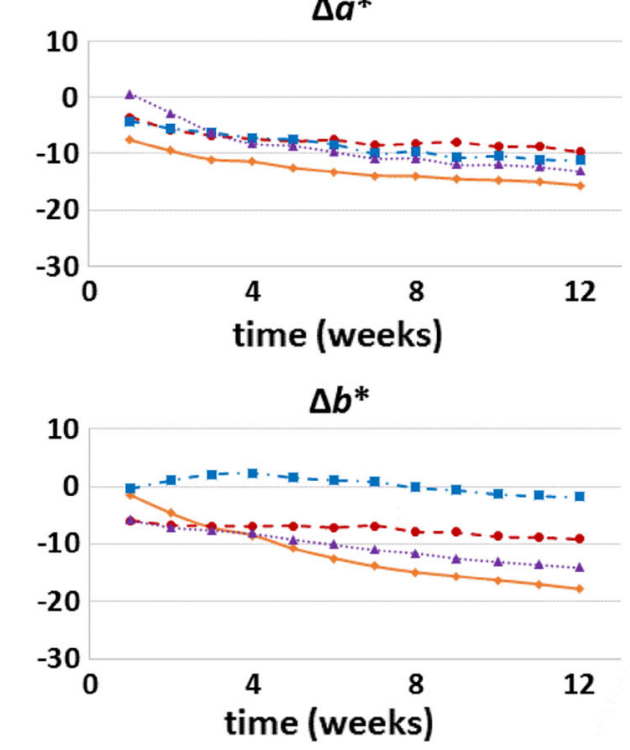

- Massaranduba ....... Jatobá impurities (see $\Delta E^{*}$ was 30.4 for kusia and 31.9 for jatobá after 12 weeks of artificial weathering in Fig. 1). It was documented by a significant loss of the original lightness and strong yellow shade, and by a milder loss of red shade (see $L^{*}, a^{*}, b^{*}$ values in Table $1 ; \Delta L^{*}, \Delta a^{*}$, $\Delta b^{*}$ values in Fig. 1). By this result, the effect of a lower density of woods for a lower colour stability of kusia and jatobá wood was proven. Generally, in Xenotest, a greying of wood surfaces occurred similarly with natural weathering, connected with increase in its green $\left(-a^{*}\right)$ and blue $\left(-b^{*}\right)$ shades. However, now the greying was not combined with darkening of wood samples due to dust particles, but it was combined with lightning $\left(+L^{*}\right)$ of samples due to washing of photodegraded dark lignin and hemicelluloses from aged surfaces, and also due to washing of darker extractives.

Jatobá wood by Costa et al. [26] is a less colour stable tropical wood species in exterior conditions. Baar and Gryc [27] observed a higher colour change in jatobá than in massaranduba wood, but only when using shorter UV exposure time in Xenotest (for $144 \mathrm{~h}$ ), and without water spraying. A lower colour stability of native jatobá in comparison with the native massaranduba wood was also found in this work, both for natural and artificial 
Fig. 3 The total colour differences $\Delta E^{*}$ and colour changes $\Delta L^{*}, \Delta a^{*}$, and $\Delta b^{*}$ of tropical woods finished with teak pigmented oil (Tk) during natural weathering for 36 months, and during artificial weathering in Xenotest for 12 weeks
Natural weathering
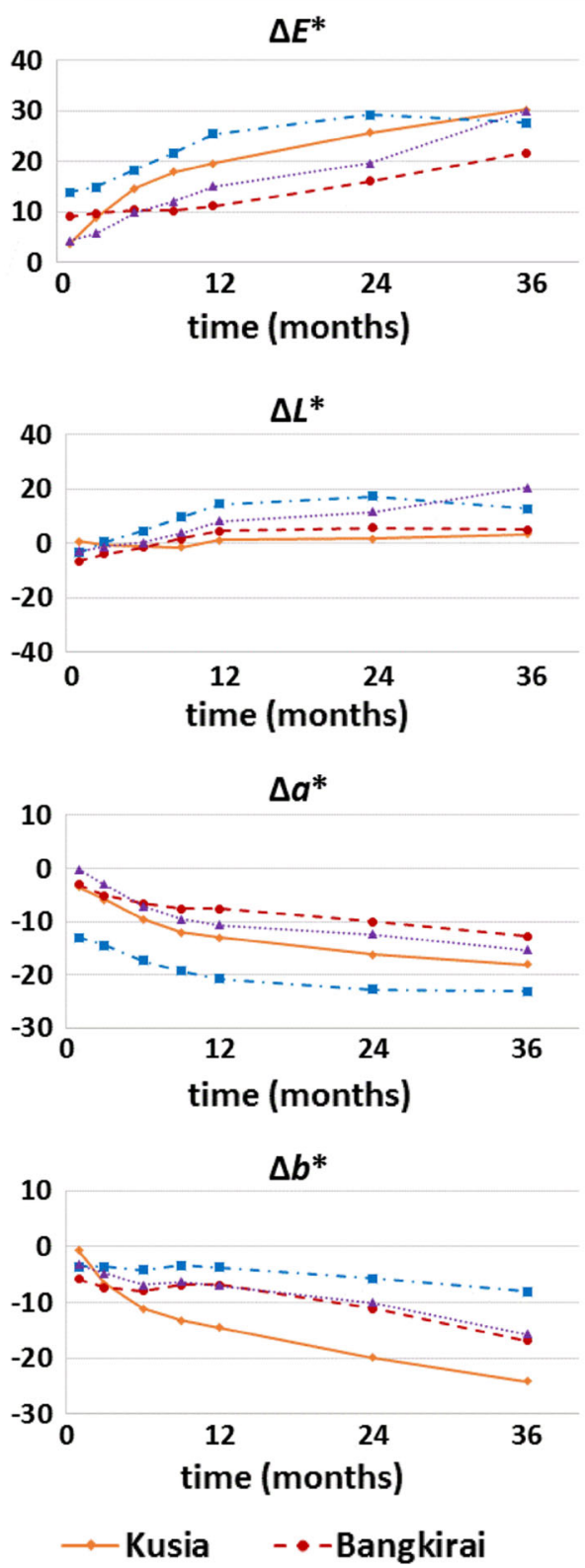

\section{Weathering in Xenotest}
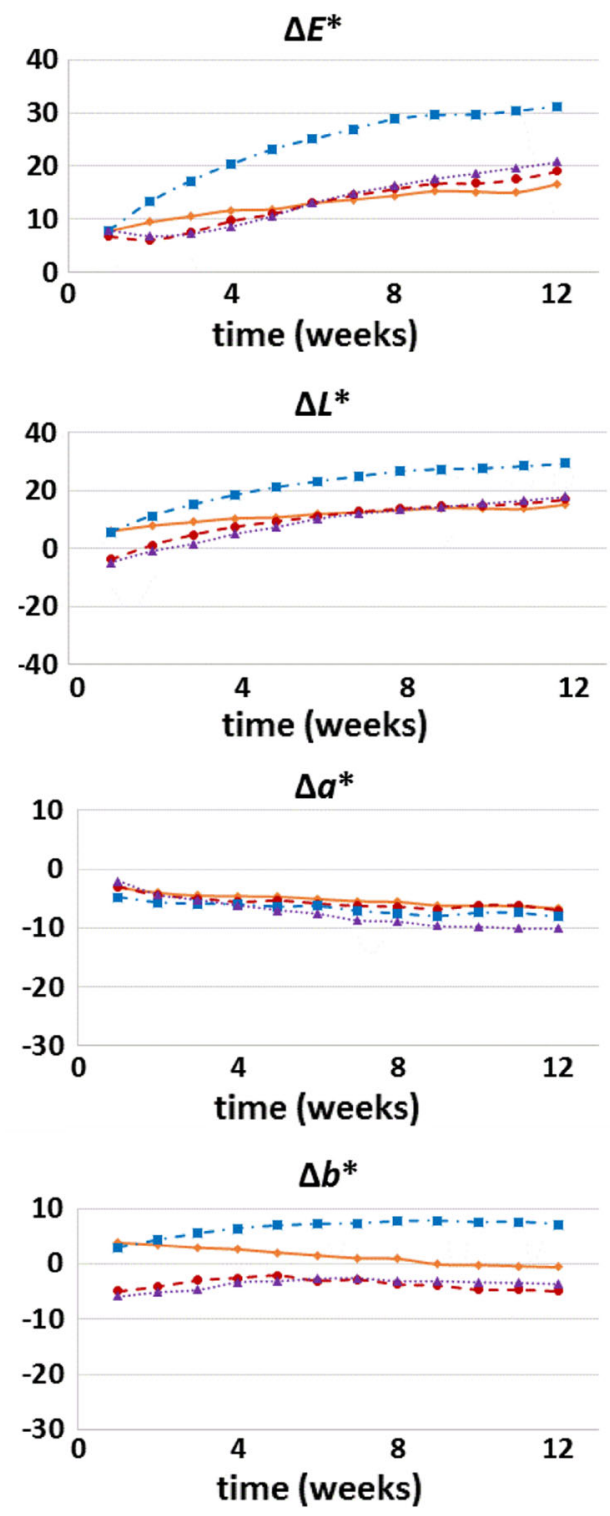

Massaranduba

Jatobá weathering (see $\Delta E^{*}$ was 25.1 for jatobá and 19.4 for massaranduba after 36 months of natural weathering and $\Delta E^{*}$ was 31.9 for jatobá and 22.5 for massaranduba after 12 weeks of artificial weathering in Fig. 1). The colour stability of the most dense woods, bangkirai and massaranduba, was a comparable in the exterior, while bangkirai was more stable in Xenotest.

An interesting result is that the colour changes of native bangkirai wood without oil treatment were the most pronounced at the beginning of natural weathering (after 1 month $\Delta E^{*}$ was 18.7 ), and then they settled the same (after 9 months $\Delta E^{*}$ was 19.3)—see Fig. 1. This could be explained by the great overall colour change of bangkirai wood during the first weeks of exposure to UV radiation in accordance with work Kishino and Nakano [28]. Further total colour changes due to action of water and penetration of dirt and dust particles into its surface layers were insignificant—or less important.

The weathering processes of native tropical woods, in most cases, confirmed the highest effect of darkening in an exterior $\left(-\Delta L^{*}\right)$ or lightening in Xenotest $\left(+\Delta L^{*}\right)$, and blueing in both an exterior and in Xenotest $\left(-\Delta b^{*}\right)$, for their total colour differences $\Delta E^{*}$ (Fig. 1). A similar result was also found in the work of Salas et al. [19]. 
Fig. 4 The total colour differences $\Delta E^{*}$ and colour changes $\Delta L^{*}, \Delta a^{*}$, and $\Delta b^{*}$ of tropical woods finished with bangkirai pigmented oil (B) during natural weathering for 36 months, and during artificial weathering in Xenotest for 12 weeks
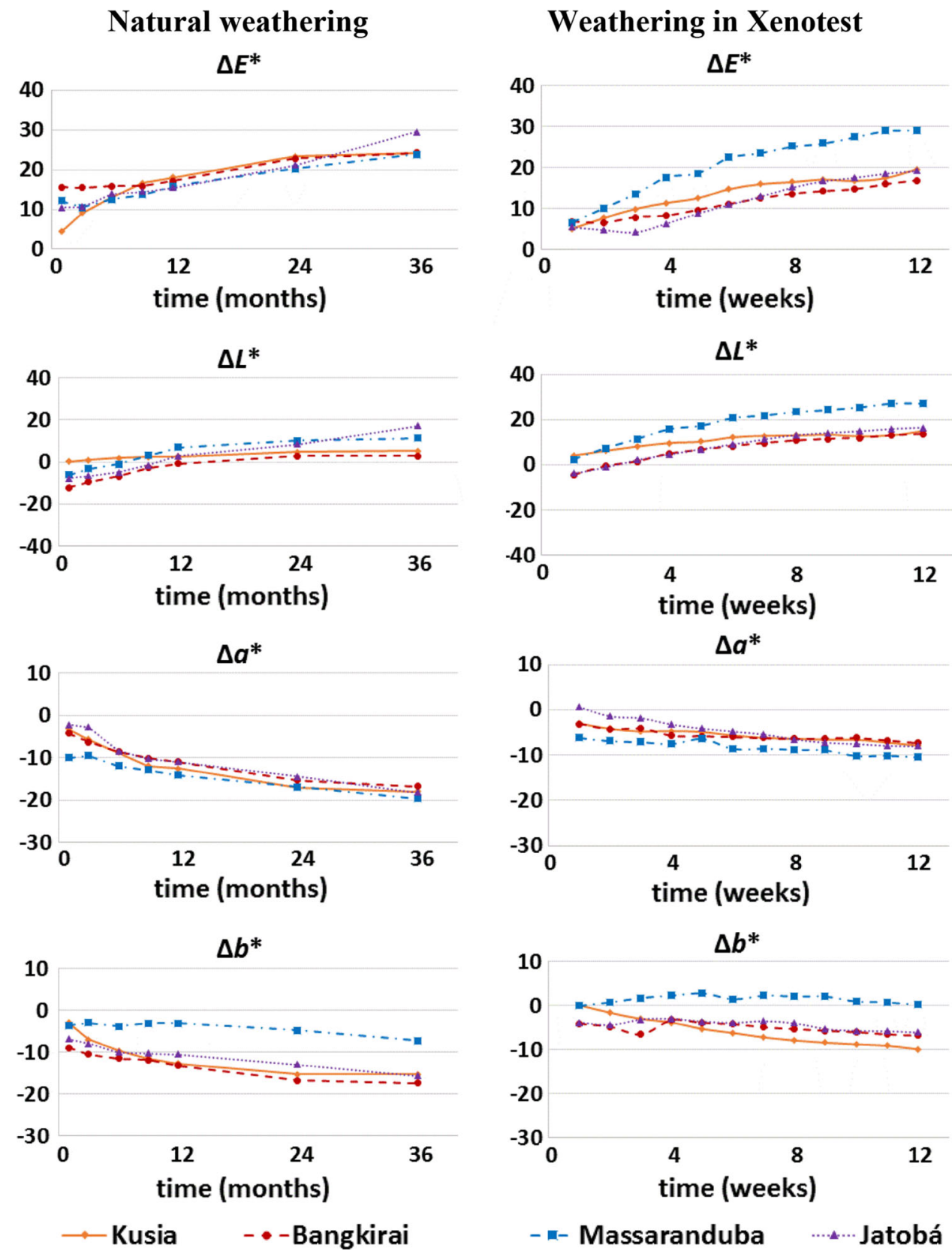
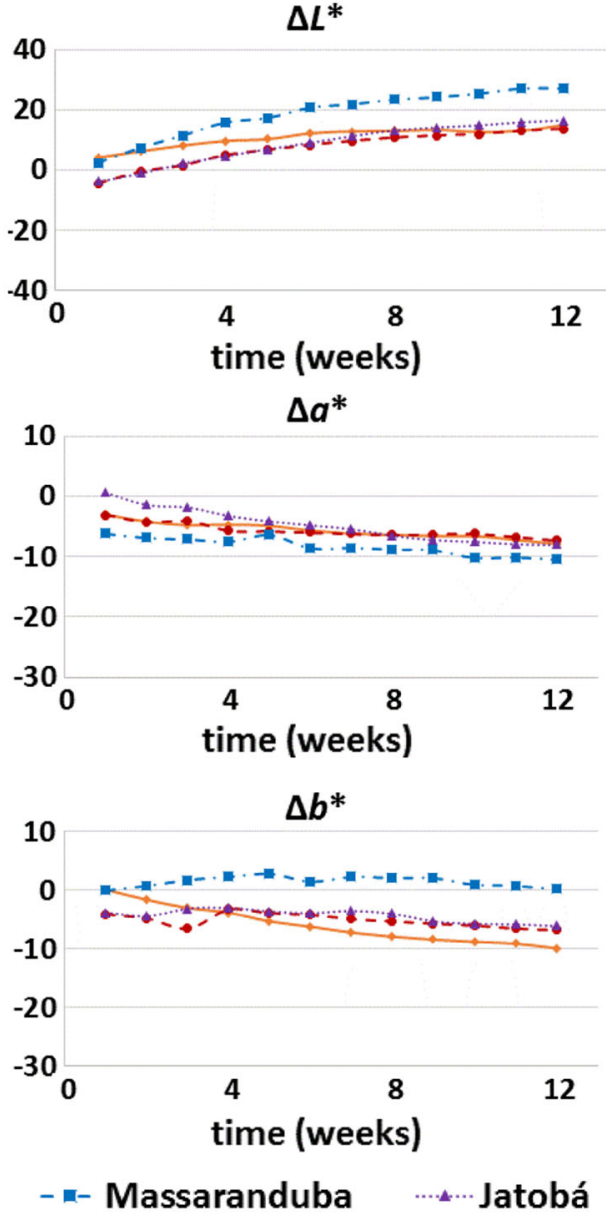

The effect of pigments in vegetable oils on the weathering of tropical woods

The mean changes of the colour parameters $\Delta L^{*}, \Delta a^{*}, \Delta b^{*}$ and the total colour difference $\Delta E^{*}$ of four tropical woods coated with three types of vegetable oils, which occurred during their natural and artificial weathering, are shown in Figs. 2, 3 and 4. The mean total colour differences $\Delta E^{*}$ arising from the natural weathering, together with the standard deviations and Duncan's tests related to woods treated with the transparent oil are shown in Table 4.
During both weathering processes, i.e. the natural and artificial, the transparent vegetable oil had the least photostabilization effect for treated tropical woods (see $\Delta E^{*}$ mainly during 12 months of weathering in Table 4 and in Figs. 2, 3, 4). Using the transparent oil, the initial colour space of bangkirai and massaranduba woods was partly preserved; however, only in the first month of the natural exposure. On the other hand, during weathering, the transparent oil applied on the surfaces of kusia wood caused even greater colour changes when compared to those which occurred in native kusia wood. 
Table 4 The total colour differences $\Delta E^{*}$ of tropical woods (kusia, bangkirai, massaranduba, jatobá) finished with the Wood Denmark vegetable oils (transparent, teak, bangkirai) during natural weathering in an exterior

\begin{tabular}{|c|c|c|c|c|c|}
\hline \multirow[t]{2}{*}{ Vegetable oil } & \multirow[t]{2}{*}{ Time of weathering (month) } & \multicolumn{4}{|c|}{$\Delta E^{*}$ (total colour difference of wood $)$} \\
\hline & & Kusia & Bangkirai & Massaranduba & Jatobá \\
\hline \multirow[t]{7}{*}{ Transparent } & 1 & $7.4(0.8)-$ & $4.8(0.9)-$ & $11.3(2.0)_{-}$ & $9.6(2.2)-$ \\
\hline & 3 & $16.1(1.7)-$ & $17.5(2.0)-$ & $13.1(0.6)-$ & $11.8(1.5)-$ \\
\hline & 6 & $22.7(1.8)-$ & $19.9(1.3)-$ & $17.1(0.5)-$ & $15.8(0.8)-$ \\
\hline & 9 & $26.9(1.4)-$ & $21.7(1.5)-$ & $20.6(0.6)-$ & $20.2(0.3)-$ \\
\hline & 12 & $29.7(0.6)-$ & $23.7(1.1)-$ & $23.8(0.5)-$ & $24.4(0.7)-$ \\
\hline & 24 & $37.3(0.5)-$ & $26.9(1.6)-$ & $24.3(1.6)-$ & $22.9(0.4)-$ \\
\hline & 36 & $30.6(0.3)-$ & $23.1(1.3)-$ & $22.9(1.0)-$ & $26.3(0.1)-$ \\
\hline \multirow[t]{7}{*}{ Teak } & 1 & $3.7(0.8) \mathrm{a}$ & $9.1(0.8) \mathrm{a}$ & $13.9(0.6) b$ & $4.4(1.2) \mathrm{a}$ \\
\hline & 3 & $8.9(0.8) \mathrm{a}$ & $9.7(1.0) \mathrm{a}$ & $15.0(0.4) \mathrm{c}$ & $5.8(1.3) \mathrm{a}$ \\
\hline & 6 & $14.7(0.6) \mathrm{a}$ & $10.3(1.1) \mathrm{a}$ & $18.3(0.9) \mathrm{d}$ & $9.8(0.9)$ a \\
\hline & 9 & $17.9(1.8) \mathrm{a}$ & $10.3(1.4) \mathrm{a}$ & $21.8(1.0) \mathrm{d}$ & $12.1(1.8) \mathrm{a}$ \\
\hline & 12 & $19.5(1.7) \mathrm{a}$ & $11.2(1.8) \mathrm{a}$ & $25.5(0.7) \mathrm{c}$ & $15.2(2.5) \mathrm{a}$ \\
\hline & 24 & $25.7(1.8) \mathrm{a}$ & $16.0(1.7) \mathrm{a}$ & $29.2(0.6) \mathrm{a}$ & 19.7 (1.9) a \\
\hline & 36 & $30.3(1.0) \mathrm{d}$ & $21.7(1.1) \mathrm{d}$ & $27.6(0.9) \mathrm{a}$ & $30.1(0.2) \mathrm{a}$ \\
\hline \multirow[t]{7}{*}{ Bangkirai } & 1 & $4.4(0.3) \mathrm{a}$ & $15.6(0.8) \mathrm{a}$ & $12.2(1.1) \mathrm{d}$ & $10.6(1.5) \mathrm{d}$ \\
\hline & 3 & $9.1(0.9) \mathrm{a}$ & $15.5(0.5) \mathrm{c}$ & $10.5(0.8) b$ & $10.6(0.8) \mathrm{d}$ \\
\hline & 6 & $13.2(0.5) \mathrm{a}$ & $15.9(0.6) \mathrm{a}$ & $12.6(0.9) \mathrm{a}$ & $14.0(1.1) \mathrm{c}$ \\
\hline & 9 & $16.6(0.4) \mathrm{a}$ & $15.8(0.5) \mathrm{a}$ & $13.7(0.8) \mathrm{a}$ & $14.5(1.1) \mathrm{a}$ \\
\hline & 12 & $18.1(0.4) \mathrm{a}$ & $17.2(0.3) \mathrm{a}$ & $16.0(0.5) \mathrm{a}$ & $15.4(0.6) \mathrm{a}$ \\
\hline & 24 & $23.3(0.2) \mathrm{a}$ & $22.9(0.4) \mathrm{a}$ & $20.3(1.0) \mathrm{a}$ & $21.2(0.3) \mathrm{d}$ \\
\hline & 36 & $24.1(0.9) \mathrm{a}$ & $24.3(0.7) \mathrm{d}$ & $23.8(1.1) \mathrm{d}$ & $29.6(0.6) \mathrm{a}$ \\
\hline
\end{tabular}

The mean values in each series are from six measurements $(n=6)$

The numbers in the parentheses are the standard deviations

Using Duncan's test, the results within samples treated with the teak and bangkirai oils were evaluated in relation to the reference samples treated with transparent oil (99.9\% significance level (a); $99 \%$ significance level (b); $95 \%$ significance level (c); and no statistical significance at $p \geq 0.05$ (d)

The aim of the Duncan's tests was to analyse the colour stabilisation effect of pigments in vegetable oils, and therefore this table does not show the results for the tropical woods in their native state- they can be seen in Fig. 1
The pigments in the vegetable oils used for treatment of tropical woods reduced their colour changes during weathering (Figs. 2, 3, 4). During natural weathering, this result for the $\Delta E^{*}$ was confirmed by a statistical analyses, as well (Table 4). The positive effect of pigments well corresponds with the work of Kropf et al. [29]. The colour stabilisation effects of teak and bangkirai pigmented oils for different wood species were expressed differently.

The lesser influence of tropical wood species on their colour changes in the initial period of exposure was observed in more works $[25,30,31]$. Similarly, in our work, oil finish in the bangkirai shade had a more positive effect on massaranduba wood. On the other hand, more colour stable for other wood species (bangkirai, kusia, jatoba) was oil finish with the teak shade. A possible explanation for this observation is that the specific type and content of different extractives in massaranduba wood influenced the colour change of the pigment in the used oil. Effect of different species of tropical woods on their colour stability after treatment with pigmented paints was also found in other works $[19,24,25]$.

Variance in the $\Delta E^{*}$ values of tropical woods treated with two types of pigmented oils were partly reduced after prolonged periods of natural weathering, and usually remained consistently lower than those in native-untreated surfaces and surfaces treated with the transparent oil (see $\Delta E^{*}$ in Table 4; Figs. 1, 2, 3, 4). A positive effect of paints on the colour stability of treated wood exists, but it is not always clear. Valverde and Moya [32] and Williams and Feist [33] also observed an insignificant improvement of the colour stability of native-untreated tropical woods by paintings' application. Richter et al. [34] observed the effect of wood species on the degradation intensity of paints on wooden products and on their colour stability. The effect of wood species and types of paint on the total colour change $\Delta E^{*}$ during artificial ageing in Xenotest was also observed by E Silva et al. [35]. 
Table 5 Linear correlations for the total colour changes $\Delta E^{*}$ between the artificial weathering in Xenotest (1-12 weeks) $(x)$ and the natural weathering in an exterior (6-36 months) (y) testing 12 compositions in one series $(n=12)$, i.e. four tropical woods (kusia, bangkirai, massaranduba, jatobá) painted with three kinds of vegetable oils (transparent, teak, bangkirai)

\begin{tabular}{llll}
\hline $\begin{array}{l}\text { Artificial } \\
\text { weathering } \\
\begin{array}{l}\text { (neeks) } \\
\text { (weest }\end{array}\end{array}$ & $\begin{array}{l}\text { Natural } \\
\text { weathering in } \\
\text { an exterior } \\
\text { (months) }\end{array}$ & $\begin{array}{l}\text { Linear } \\
\text { regression for } \\
\Delta E^{*}\end{array}$ & $\begin{array}{l}\text { Coefficient of } \\
\text { determination } \\
R^{2}\end{array}$ \\
\hline 1 & 6 & $1.03 x+8.04$ & 0.28 \\
& 12 & $1.37 x+10.22$ & 0.24 \\
& 24 & $2.00 x+9.90$ & 0.52 \\
4 & 36 & $0.88 x+19.88$ & 0.27 \\
& 6 & $0.41 x+9.38$ & 0.43 \\
& 12 & $0.75 x+9.06$ & 0.68 \\
& 24 & $0.58 x+15.73$ & 0.41 \\
& 36 & $-0.01 x+26.22$ & 0.00 \\
& 6 & $0.30 x+8.78$ & 0.36 \\
& 12 & $0.57 x+7.64$ & 0.60 \\
& 24 & $0.41 x+15.34$ & 0.31 \\
& 36 & $-0.01 x+26.24$ & 0.00 \\
& 6 & $0.26 x+8.74$ & 0.30 \\
& 12 & $0.51 x+6.99$ & 0.55 \\
& 24 & $0.33 x+15.76$ & 0.23 \\
& 36 & $-0.01 x+26.50$ & 0.00 \\
\hline
\end{tabular}

Massaranduba wood finished with pigmented oils appeared to be the less photostable during artificial weathering in Xenotest (see $\Delta L^{*}$ and $\Delta E^{*}$ in Figs. 3, 4. $\Delta E^{*}$ was 31.2 with teak pigmented and 29.2 with bangkirai pigmented oil after 12 weeks of artificial weathering). In this case, significant lightening $\Delta L^{*}$ and a high total colour difference $\Delta E^{*}$ were observed. This result can be explained by its initial darkest shade before ageing $\left(L^{*}=49.0\right)$ compared to other tested tropical woods (Table 1).

Generally, of the tested tropical woods, bangkirai wood was the most colour stable in both cases, i.e. natural and with oil finishes. In Xenotest, it was always resistant to colour changes independently if it was not treated (see $\Delta E^{*}$ in Fig. 1), or was treated with transparent or pigmented oils (see $\Delta E^{*}$ in Figs. 2, 3, 4). In outdoor areas, it had good long-term colour stability after treatment with teak pigmented oil (see $\Delta E^{*}$ in Fig. 3).

\section{Correlations and modelling of colour changes of painted wood between natural and artificial weathering}

The linear correlations for the total colour differences $\Delta E^{*}$ achieved between artificial and natural weathering are shown in Table 5, and for two selected cases also in Fig. 5. Linear correlation analysis showed some of the modelling possibilities of natural weathering in an exterior by means of artificial ageing in Xenotest. However, the achieved results were not always clear (Table 5).

The maximal correspondences for the $\Delta E^{*}$ were achieved between weathering that lasted 1 week in Xenotest and 24 months in an exterior $\left(R^{2}=0.52\right)$, 4 weeks in Xenotest and 12 months in an exterior $\left(R^{2}=0.68\right.$-see also Fig. 5a), 8 weeks in Xenotest and 12 months in an exterior $\left(R^{2}=0.60\right)$, and 12 weeks in Xenotest and 12 months in an exterior $\left(R^{2}=0.55\right)$ (Table 5). An interesting result is that 1 week of accelerated weathering modelled quite accurately 2 years of exterior weathering. After a longer period of testing in an exterior, the coefficient of determination decreased (Table 5; see also Fig. 5b with $\left.R^{2}=0.41\right)$. Correspondences for the $\Delta E^{*}$ comparing both
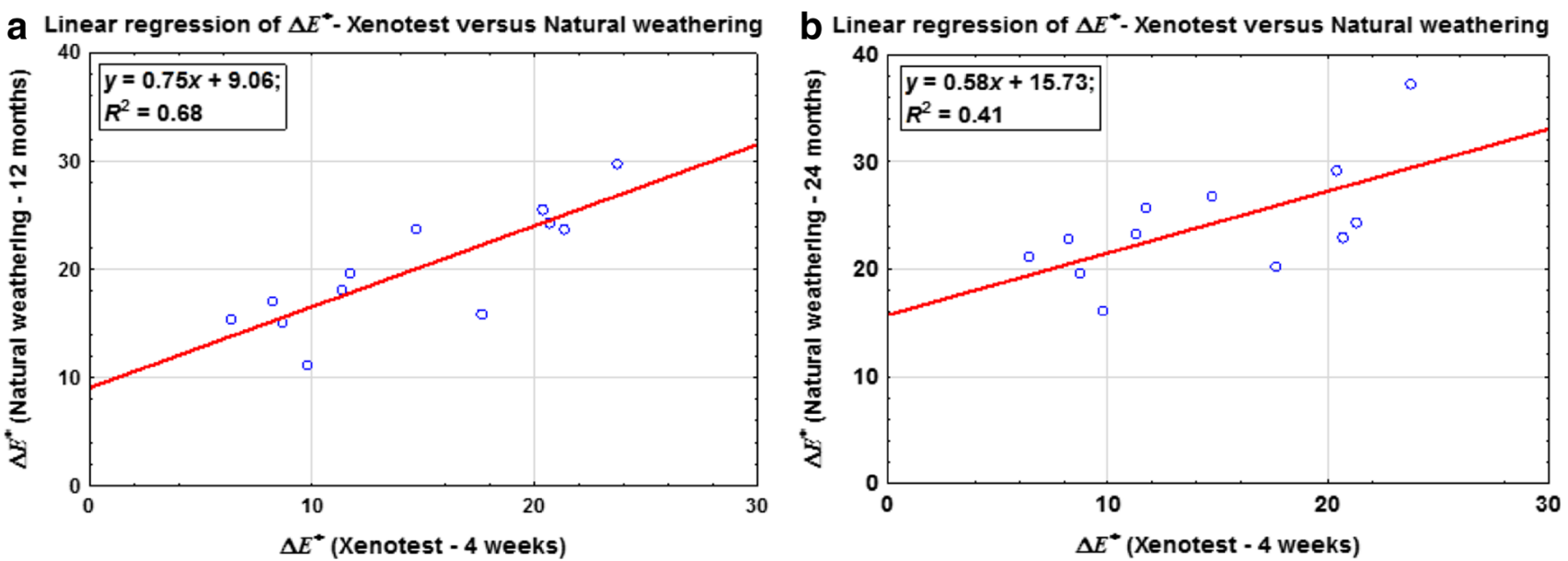

Fig. 5 Linear correlations for the total colour changes $\Delta E^{*}$ between artificial weathering in Xenotest (4 weeks) and natural weathering in exterior (12 or 24 months) for four tropical woods painted with three kinds of vegetable oils 
weathering methods were a slightly lower after 6 months of natural weathering, connected with a small decreasing of the value of $R^{2}$ (Table 5). So, finally it can be seen that the best similarity of the total colour changes $\Delta E^{*}$ in the Xenotest for 12 series of painted tropical woods (four species with three oils) was observed after 12 months of weathering in the exterior (Figs. 2, 3, 4; Table 5).

During longer periods of natural weathering from 24 to 36 months, colours with oil-painted tropical woods remain grey only with a partial change of colour coordinates $\Delta a^{*}$, $\Delta b^{*}$ due to absorption of dust particles into surface layers and leaching of degradation components from cell walls. In the opposite case, during Xenotest accelerated ageing in clear air and spray water conditions [21], some larger differences of colours of tested woods and paints were also observed after longer testing time. This was then connected with a significant decrease of the coefficient of determination $\left(R^{2}\right)$ for the linear correlations of the $\Delta E^{*}$ between two ageing methods (Table 5).

From the experimental results, it is evident, that the colour stability of painted tropical woods during artificial weathering in Xenotest was often different compared to their stability during natural weathering in an exterior. This is more or less closely connected with different processes of degradation-leaching of extractives and depolymerized lignin from surface layers using these two ageing methods $[13,16]$. The effects of dust particles also influenced colour changes in the exterior [7]. A problem of comparison of results from these two weathering methods was already discussed in the works of Závada [36], Valverde and Moya [11] and Grüll et al. [13]. The necessity of additional exterior tests for more exact results was proposed by Crewdson and Ketola [37]. Although light from the xenon lamps is observed as the best simulating process of sunlight degradation [12, 38], in the model accelerated weathering process, different results can be achieved due to absence of dust which causes darkening of wood surfaces degraded by UV- and VIS-light and water in the exterior.

Generally, modelling of painted wood weathering is a very complicated process. The results of different scientific works give various conclusions $[11,13,36]$ and research works are still not finished. The benefit of this work was the determination that for modelling the colour change of wood in the exterior, it is sufficient to use only Xenotest weathering that lasts a defined time-e.g. 4 weeks in this work. Longer periods of artificial ageing did not affect refining the significance.

Overall, it is possible to say that the finishing vegetable Woca Denmark oils stabilised the colour of tropical woods only during shorter exposure, and mainly if pigmented oils were used. This can be explained by a lower permeability of exotic woods, when a lower penetration of oils could not save surface layers of wood for a longer time [24]. Vegetable oils only impregnated the surface layers of wood, and result was a faster washout of oils due to the weathering. The painted surfaces of wood must be regularly renewed, and thus it is possible, mainly through pigmented treatment adjustments, to keep colour fastness in exterior exposures.

\section{Conclusion}

The aim of this research was to study the effects of transparent and pigmented vegetable oils on the colour stability of selected tropical woods at their natural and artificial weathering. The colour changes of tested tropical wood species in the outdoor exposition in the Central European climate conditions were already highly significant after 6 months. The most colour stable wood species was bangkirai, without or with oil treatment.

Using oil paints, the colour change of treated wood can be mitigated, especially using pigmented ones. To achieve stable colours of oiled wood surfaces, they must be renewed frequently, optimally within 6-12 months.

The supposed total colour change of tested tropical woods in the exterior could be modelled by Xenotest in some cases but results were not always clear.

Acknowledgments This research was funded by the Grant Agency of the Slovak Republic, Project APVV-0200-12 and by Grant Agency of the Faculty of Forestry and Wood Sciences, Project No. 20143127. The authors would like also to thank Ms. E. Durčíková for her technical assistance.

\section{References}

1. Pastore TCM, Santos KO, Rubim JC (2004) A spectrocolorimetric study on the effect of ultraviolet irradiation of four tropical hardwoods. Bioresour Technol 93:37-42

2. Yamauchi S, Sudiyani Y, Imamura Y, Doi S (2004) Depth profiling of weathered tropical wood using Fourier transform infrared photo-acoustic spectroscopy. J Wood Sci 50:433-438

3. Pandey KK (2005) A note on the influence of extractives on the photo-discoloration and photo-degradation of wood. Polym Degrad Stab 87:375-379

4. Barreto CCK, Pastore TCM (2009) Resistance to artificial weathering of four tropical woods: the effects of the extractives. Cienc Florest 19:23-30

5. Sudiyani Y (1999) Chemical characteristics of surfaces of hardwood and softwood deteriorated by weathering. J Wood Sci 45:348-353

6. Sudiyani Y, Imamura Y, Doi S, Yamauchi S (2003) Infrared spectroscopic investigations of weathering effects on the surface of tropical wood. J Wood Sci 49:86-92

7. Evans PD (2008) Weathering and photoprotection of wood. ACS Symp Ser 982:69-117

8. Williams RS, Miller R, Gangstad J (2001) Characteristics of ten tropical hardwoods from certified forests in Bolivia. Part 1: weathering characteristics and dimensional change. Wood Fiber Sci 33:618-626 
9. Pandey KK (2005) Study of the effect of photo-irradiation on the surface chemistry of wood. Polym Degrad Stab 90:9-20

10. Mattos BD, De Cademartori PHG, Lourençon TV, Gatto DA (2014) Colour changes of Brazilian eucalypts wood by natural weathering. Int Wood Prod J 5(1):33-38

11. Valverde JC, Moya R (2014) Correlation and modeling between color variation and quality of the surface between accelerated and natural tropical weathering in Acacia mangium, Cedrela odorata and Tectona grandis wood with two coating. Color Res Appl 39:519-529

12. Forsthuber B, Schaller C, Grüll G (2013) Evaluation of the photo stabilising efficiency of clear coatings comprising organic UV absorbers and mineral UV screeners on wood surfaces. Wood Sci Technol 47:281-297

13. Grüll G, Tscherne F, Spitaler I, Forsthuber B (2014) Comparison of wood coating durability in natural weathering and artificial weathering using fluorescent UV-lamps and water. Eur J Wood Wood Prod 72:367-376

14. Creemers J, De Meijer M, Zimmermann T, Sell J (2002) Influence of climatic factors on the weathering of coated wood. Holz Roh Werkst 60:411-420

15. Schnabel T, Zimmer B, Petutschnigg AJ (2009) On the modelling of colour changes of wood surfaces. Eur J Wood Wood Prod 67:141-149

16. Rüther P, Jelle BP (2013) Color changes of wood and woodbased materials due to natural and artificial weathering. Wood Mater Sci Eng 8(1):13-25

17. EN 927-3 (2006) Paints and varnishes-coating materials and coating systems for exterior wood-Part 3: natural weathering test. European Committee for Standardization, Brussels

18. EN 927-3 (2006) Paints and varnishes-Coating materials and coating systems for exterior wood-Part 6: exposure of wood coatings to artificial weathering using fluorescent UV lamps and water. European Committee for Standardization, Brussels

19. Salas C, Moya R, Vargas-Fonseca L (2014) Optical performance of finished and unfinished tropical timbers exposed to ultraviolet light in the field in Costa Rica. Wood Mater Sci Eng 9(1):1-17

20. Sarvašová I (2015) Development of Arboretum Borová hora tree species collection in the period 2005-2014. Dendroflora of Central Europe-utilization of knowledge in research, education and practice. Technical University in Zvolen, Slovakia, pp 101-108

21. Leštianska A, Vido J, Střelcová K (2014) Evaluation of extremity climatic characteristics in the Zvolenská valley and its surrounding in different forest vegetation levels during the vegetation seasons 2009-2013. Transport of water, chemicals and energy in the soil-plant-atmosphere system, vol 21. International Poster Day and Institute of Hydrology Open Day, Institute of Hydrology SAS, Bratislava, pp 159-170

22. CIE (1986) Colorimetry, 2nd edn, CIE Pub. No. 15.2. Commission Internationale de l'Eclairage, Vienna, p 74

23. Kataoka Y, Kiguchi M, Fujiwara T, Evans PD (2005) The effects of within-species and between-species variation in wood density on the photodegradation depth profiles of sugi (Cryptomeria japonica) and hinoki (Chamaecyparis obtusa). J Wood Sci 51:531-536

24. Van den Bulcke J, Rijckaert V, Van Acker J, Stevens M (2006) Adhesion and weathering performance of waterborne coatings applied to different temperate and tropical wood species. J Coat Technol 3(3):185-191

25. De Windt I, Van den Bulcke J, Wuijtens I, Coppens H, Van Acker J (2014) Outdoor weathering performance parameters of exterior wood coating systems on tropical hardwood substrates. Eur J Wood Wood Prod 72:261-272

26. Costa JA, Gonçalez JC, Camargos JAA, Gomes IAS (2011) Photodegradation of two tropical wood species: jatobá (Hymenaea courbaril) and tauari (Couratari oblongifolia) submitted to ultraviolet radiation. Cerne 17(1):133-139

27. Baar J, Gryc V (2012) The analysis of tropical wood discoloration caused by simulated sunlight. Eur J Wood Wood Prod 70:263-269

28. Kishino M, Nakano T (2004) Artificial weathering of tropical woods. Part 2: color change. Holzforschung 58:558-565

29. Kropf FW, Sell J, Feist WC (1994) Comparative weathering tests of North American and European exterior wood finishes. For Prod J 44:33-41

30. Custódio JEP, Eusébio MI (2006) Waterborne acrylic varnishes durability on wood surfaces for exterior exposure. Prog Org Coat 56:59-67

31. Podgorski L, Merlin A, Deglise X (1996) Analysis of the natural and artificial weathering of a wood coating by measurement of glass transition temperature. Holzforschung 50:282-287

32. Valverde JC, Moya R (2010) Effect of weathering on color of two coating applied on Cedrela odorata and Carapa guianensis wood. Maderas Cienc Tecnol 12(3):171-180

33. Williams RS, Feist WC (1994) Effect of pre-weathering, surface roughness, and wood species on the performance of paint and stains. J Coat Technol 66:109-121

34. Richter HG, Schwab E, Von Arps-Aubert T, Nock HP (2004) Quality assessment of laminated window scantlings from mixed tropical hardwoods after long-term exposure to weathering. J Trop For Sci 16:350-356

35. E Silva JO, Pastore TCM, Pastore F Jr (2007) Resistance to artificial weathering of five tropical woods and of two finish products. Cienc Florest 17:17-23

36. Závada V (2010) The light stability of transparent coating materials is influenced by the location of exposition. Acta Universitatis Agriculturae et Silviculturae Mendelianae Brunensis 58:239-258

37. Crewdson MJ, Ketola WD (2009) Best practices in weathering: outdoor and accelerated testing compared. Eur Coat J 4:116-121

38. Tolvaj L, Mitsui K (2005) Light source dependence of the photodegradation of wood. J Wood Sci 51:468-473 